\title{
Relationship among Welding Defects with Convection and Material Flow Dynamic Considering Principal Forces in Plasma Arc Welding
}

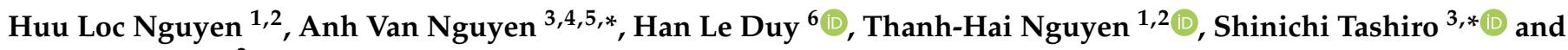 \\ Manabu Tanaka ${ }^{3}$ \\ 1 Faculty of Mechanical Engineering, Ho Chi Minh City University of Technology (HCMUT), \\ 268 Ly Thuong Kiet Street, District 10, Ho Chi Minh City 700000, Vietnam; nhloc@hcmut.edu.vn (H.L.N.); \\ haint@hcmut.edu.vn (T.-H.N.) \\ 2 Viet Nam National University Ho Chi Minh City, Linh Trung Ward, Thu Duc District, \\ Ho Chi Minh City 700000, Vietnam \\ 3 Joining and Welding Research Institute, Osaka University, Osaka 567-0047, Japan; tanaka@jwri.osaka-u.ac.jp \\ 4 Murata Welding Laboratory, Osaka 532-0012, Japan \\ 5 Welding Engineering and Laser Processing Centre, Cranfield University, Cranfield MK43 0AL, UK \\ 6 School of Mechanical Engineering, Hanoi University of Science and Technology, Hanoi 100-000, Vietnam; \\ duy.hanle@hust.edu.vn \\ * Correspondence: nguyen.van-anh@cranfield.ac.uk (A.V.N.); tashiro@jwri.osaka-u.ac.jp (S.T.)
}

check for updates

Citation: Nguyen, H.L.; Van Nguyen, A.; Duy, H.L.; Nguyen, T.-H.; Tashiro, S.; Tanaka, M. Relationship among Welding Defects with Convection and Material Flow Dynamic Considering Principal Forces in Plasma Arc Welding. Metals 2021, 11, 1444. https://doi.org/10.3390/met11091444

Academic Editors: Michael Rethmeier and Wei Zhou

Received: 3 July 2021

Accepted: 7 September 2021

Published: 13 September 2021

Publisher's Note: MDPI stays neutral with regard to jurisdictional claims in published maps and institutional affiliations.

Copyright: (c) 2021 by the authors. Licensee MDPI, Basel, Switzerland. This article is an open access article distributed under the terms and conditions of the Creative Commons Attribution (CC BY) license (https:/ / creativecommons.org/licenses/by/ $4.0 /)$.
Abstract: The material flow dynamic and velocity distribution on the melted domain surface play a crucial role on the joint quality and formation of welding defects. In this study, authors investigated the effects of the low and high currents of plasma arc welding on the material flow and thermodynamics of molten pool and its relationship to the welding defects. The high-speed video camera (HSVC) was used to observe the convection of the melted domain and welded-joint appearance. Furthermore, to consider the Marangoni force activation, the temperature on the melted domain was measured by a thermal HSVC. The results revealed that the velocity distribution on the weld pool surface was higher than that inside the molten weld pool. Moreover, in the case of $80 \mathrm{~A}$ welding current, the convection speed of molten was faster than that in other cases (120 A and $160 \mathrm{~A})$. The serious undercut and humping could be seen on the top surface (upper side) and unstable weld bead was visualized on the back side (bottom surface). In the case of 160 A welding current, the convection on the weld pool surface was much more complex in comparison with $80 \mathrm{~A}$ and $120 \mathrm{~A}$ cases. The excessive convex defect at the bottom side and the concave defect at the top surface were observed. In the case of $120 \mathrm{~A}$ welding current, two convection patterns with the main flow in the backward direction were seen. Almost no welding defect could be found. The interaction between the shear force and Marangoni force played a solid state on the convection and heat transportation processes in the plasma arc welding process.

Keywords: plasma arc welding; thermodynamic; material flow; velocity distribution; welding current

\section{Introduction}

The thermodynamic of the molten material flow at the melted domain in welding processes and metal additive manufacturing (AM) using laser and arc heat sources plays a principal role on the joint-quality and the appearance of defects such as porosity [1], pore [2], undercut [3], humping [4], and spatter [5]. Recently, observation technologies have contributed significantly to clarify the behavior of the material flow in both welding processes and metal AM. Using high speed cameras and innovative X-ray radiography image systems, the convection at the melted domain was estimated in laser welding [6,7] and the friction stir welding process [8]. In another way, using X-ray synchrotron observation systems with a high energy beamline, the keyhole behavior, porosity, and fluid flow 
dynamic were employed in metal laser welding and AM processes in the UK $[9,10]$, the US [11,12], and Japan [13,14].

Plasma arc welding (PAW) is one advanced joining technology with superior characteristics such as: high current density, constricted arc plasma, and high plasma jet velocity. In PAW, the interaction among plasma arc pressure, plasma gas flow, material flow behavior with the metallurgy phenomena, microstructure formation, and joint quality is very complex. The physical nature behind these processes are inadequately understood owing to the complex material flow thermodynamics that occur in a very short time and under extreme conditions.

In the relation between the material flow process and joint quality, some papers addressed steel and aluminum. Anh et al. [15] reported the effect of the pilot gas component on the behavior of convection flow in the case of SUS 304 material. The result showed that in the case of pilot gas (Ar gas) mixtured with $10 \% \mathrm{He}$, the heat input density is much increased and the weld bead becomes wider in comparison to the pure Ar case, especially on the top side. In another paper, Nguyen et al., [16] observed the material flow and keyhole formation at the same time. The results showed that at the cutting arc period the keyhole boundary changed significantly, especially in the longitudinal section. With the support of innovative X-ray image technology, Wu et al. [17] found out that the dominant forces of material flow behavior in PAW were the arc pressure and shear force. Among them, the arc pressure principally contributes to the formation of the keyhole and the shear force corresponds to the formation of the weld pool. Bin et al. [18] experimented with aluminum and indicated the difference between the material flow in the cases of steel and aluminum. The results showed that the velocity was much lower in the case of aluminum due to its low mass density. In a recent paper, Manh et al. [19] verified by experiment that the fluid dynamics of the weld pool in PAW was controlled mainly by shear force. This is totally different to the Tungsten inert gas (TIG) welding process in which the molten flow is mainly controlled by Marangoni force.

However, due to the difficulty of measurement of the material flow of melted domains at high temperature and extreme brightness, the investigations progressed slowly. To overcome this trouble, another approach using calculated tools through numerical simulation has been performed as an efficient alternative method to exploit this behavior, furthermore for controlling efficiently this welding process. Rubinsky et al. utilized a two-dimensional model [20] and a three-dimensional model [21] of thermodynamic and material flow for the melted zone. The results displayed the correlation between the velocity and temperature in vertical cross-sections and horizontal cross-sections of melted domain according to the alteration of welding speed. Wu's team developed a two-dimensional model [22] and a three-dimensional model [23] considering the coupled plasma arc-keyhole-weld pool interactions for calculating the heat transportation and material flow dynamic inside the molten pool. Predicted results showed two main convections inside the melted domain including one outwards eddy along the top surface and another one downwards eddy along the keyhole wall. Recently, Pan et al. [24] predicted the material flow of the molten zone in the stationary welding condition (no movement of the torch or workpiece). They indicated that two eddies were formed inside the melted domain. This fluid flow dynamic is controlled by four driving forces including electromagnetic force, Marangoni force, buoyancy force, and shear force as explained in [25].

In view of the foregoing discussions on publications, it is apparent that predictions on the fluid flow thermodynamic considering the interaction with the melted domain and keyhole contour have been made; however, a whole picture of the relationship among plasma arc-keyhole formation, the behavior of material flow, and joint quality has not been clarified yet. For an in-depth understanding of the behavior of the material flow at the melted domain, a series of investigations of influence of welding parameters were carried out.

At the first step, we adopted the effect of plasma gas flow rate [15] on the eddy formation and the relationship between them to welding defects. In another paper, we discussed 
the dynamic of material flow inside the melted domain with the change of welding current [26]. In this case, only the material flow inside the weld pool was considered without the detailed discussion of driving forces. This investigation was adopted to elucidate the material flow dynamic, velocity, and temperature on the surface of the melted domain. Furthermore, an essential discussion on the welding defect formation and the activation of dominant forces was explored.

\section{Experimental Method}

Figure 1 presents an experimental setup for this investigation. The welding equipment was included: plasma welding machine NW-300ASR made by Nippon Steel Company (Tokyo, Japan) and a plasma torch with maximal welding current $300 \mathrm{~A}$. A high-speed video camera (HSVC) (Memrecam Q1v-V-209-M8, Nac Co., Ltd., Osaka, Japan) was perpendicular with the welding seam at a $45^{\circ}$ angle with workpiece surface to take photographs of the melted domain surface. The back gas was controlled by a small box to cover the lower side of the melted domain without the negative influence from the environment.
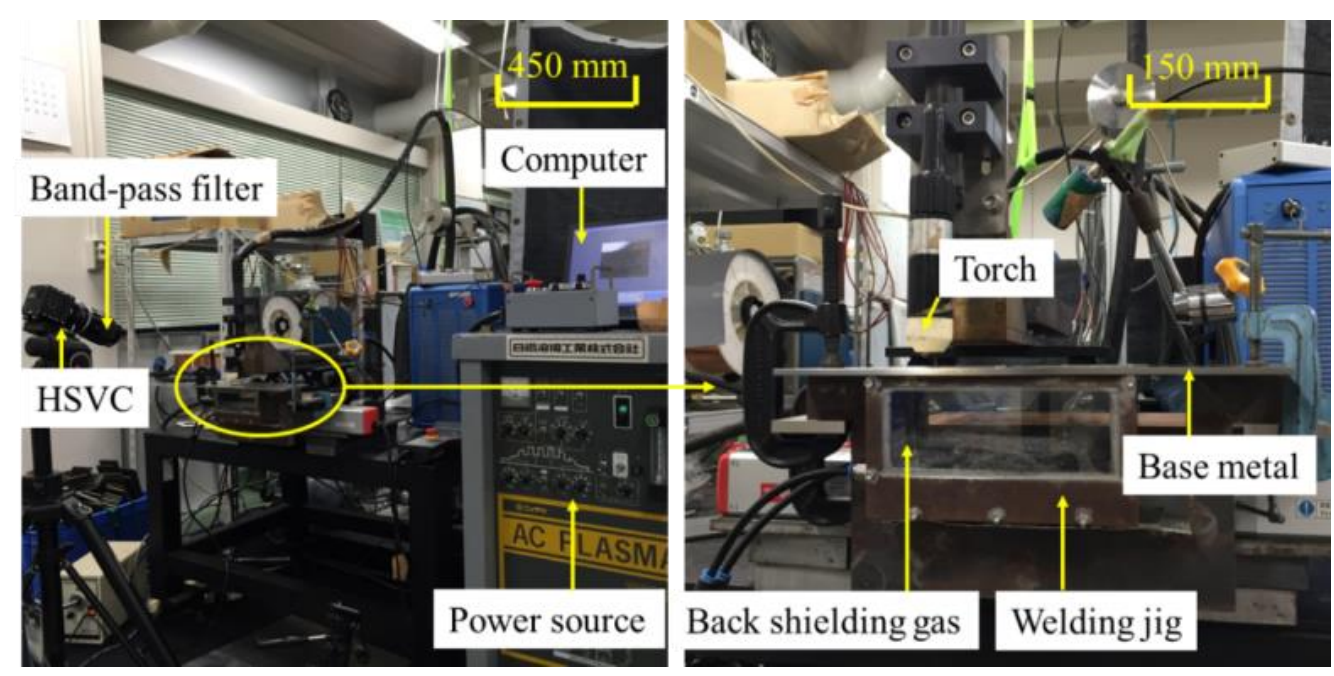

Figure 1. Photograph of the experimental setup.

A diagram of the experimental setup is described in Figure 2. In this investigation, the main current is changed at three levels: DC 80,120, or $160 \mathrm{~A}$. The setback for the tungsten electrode was $3 \mathrm{~mm}$. Tungsten electrode diameter was $2.4 \mathrm{~mm}$. Plasma nozzle was $2.0 \mathrm{~mm}$. The arc length was fixed at $5 \mathrm{~mm}$. The workpiece was SUS304 plates with a $4 \mathrm{~mm}$ thickness. The torch travel speed was $3 \mathrm{mms}^{-1}$. The torch shielding gas, the back gas, and the pilot gas were pure Ar with the gas flow rate of $7.5 \operatorname{lmin}^{-1}, 5.0 \mathrm{lmin}^{-1}$, and $1.7 \mathrm{lmin}^{-1}$ respectively.

In order to estimate the convection, tracer particles (zirconia) with a diameter of $0.03 \mathrm{~mm}$ were used. Based on the trajectory and position of particles, the fluid dynamics (convection, material flow and flow velocity) of the melted domain can be elucidated through Dipp-motion software ( Detect Co., Ltd., Osaka, Japan). For the experiments, holes on the workpiece surfaces were created and zirconia tracers were pushed in before welding. Three holes in a straight-line were made along the welding seam. Then, 5 zirconia seeds were pushed in each hole. However, in the case of $160 \mathrm{~A}$, because the size of the weld pool surface is large and long, with a HSVC setting position, it is impossible to visualize the whole melted domain. In order to overcome this difficulty, the zirconia tracers were fed to the motel pool surface by two ways: around the keyhole before welding through the holes on the workpiece surfaces (as indicated above) and at the middle part of the molten pool during welding by a supply device. Details for this supply technique can be seen in our recent paper [27]. 


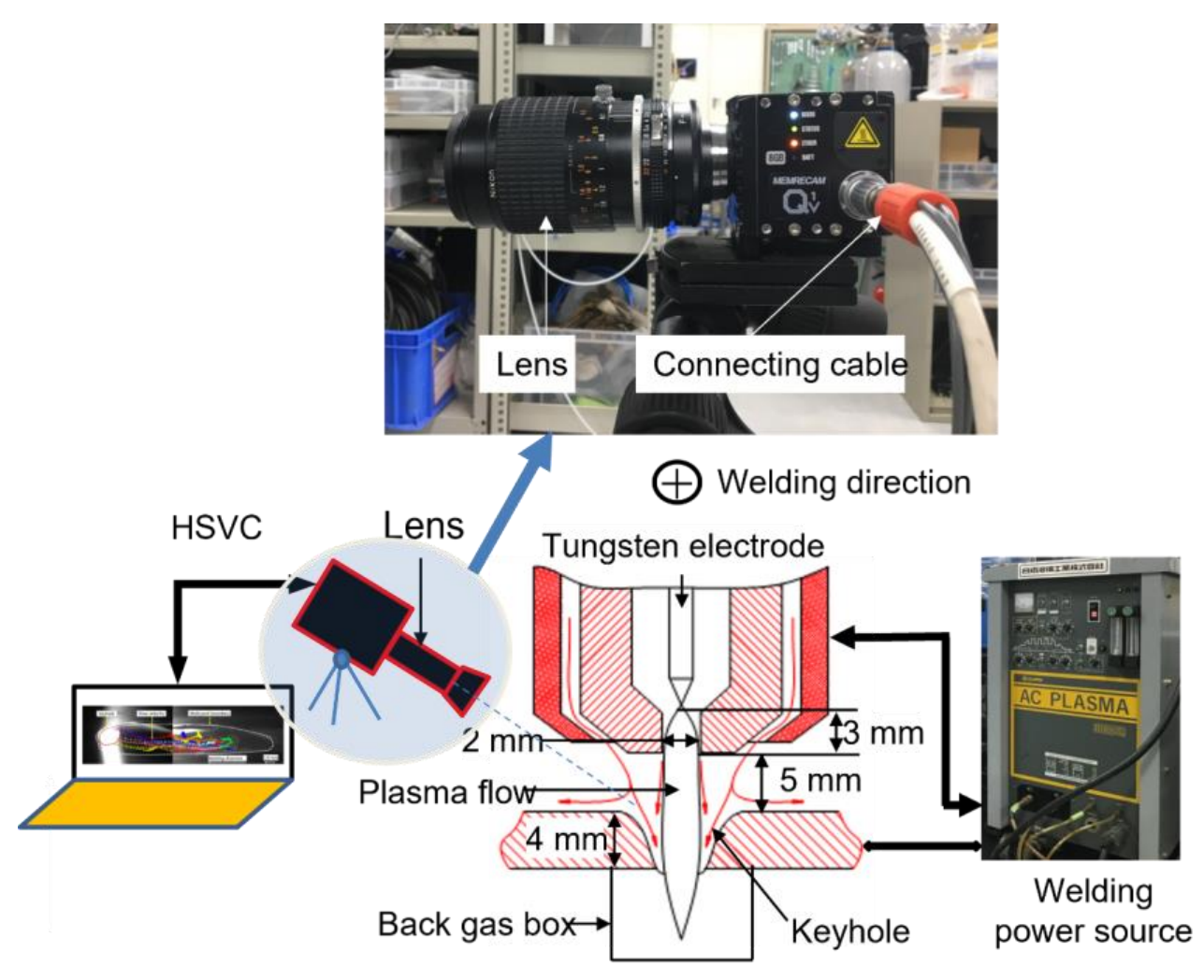

Figure 2. A diagram of the experimental setup for observing material flow on the melted domain surface.

Figure 3 indicates a typical image of this visualization. In this case, because the intensity of the arc plasma is too high, the movement of particles around the keyhole is difficult to visualize clearly. In order to overcome this problem, a diode laser apparatus with the power of $30 \mathrm{~W}$ and the wavelength of $940 \mathrm{~nm}$ was utilized [19]. The laser head was adapted to cut mostly the brightness of the arc plasma. As a result, the whole melted domain surface can be seen clearly.

To discuss the influence of driving forces on the convection and the heat transport, a temperature measurement on the melted domain surface was performed. A schematic can be found in Figure 4. In this case, a Phantom V4 thermal camera (Phantom Co., Ltd., Tokyo, Japan) was utilized. The measurement mechanism is based on two-color pyrometry [19]. The frame rate was $2000 \mathrm{pfs}$. The camera was perpendicular to weld seam. Due to the high brightness of the arc during welding, the temperature on the melted domain surface is impossible to measure accurately. To overcome this issue, the measurement was taken into a period of off welding power source (about $0.01 \mathrm{~ms}$ after arc disappearance by breaking automat suddenly). It was confirmed by experiment that the decrease of temperature was very slight. Then, this change could be ignored, and the result could be utilized to explain the visualization data in this paper. More details of this measurement can be read in ref [19]. 


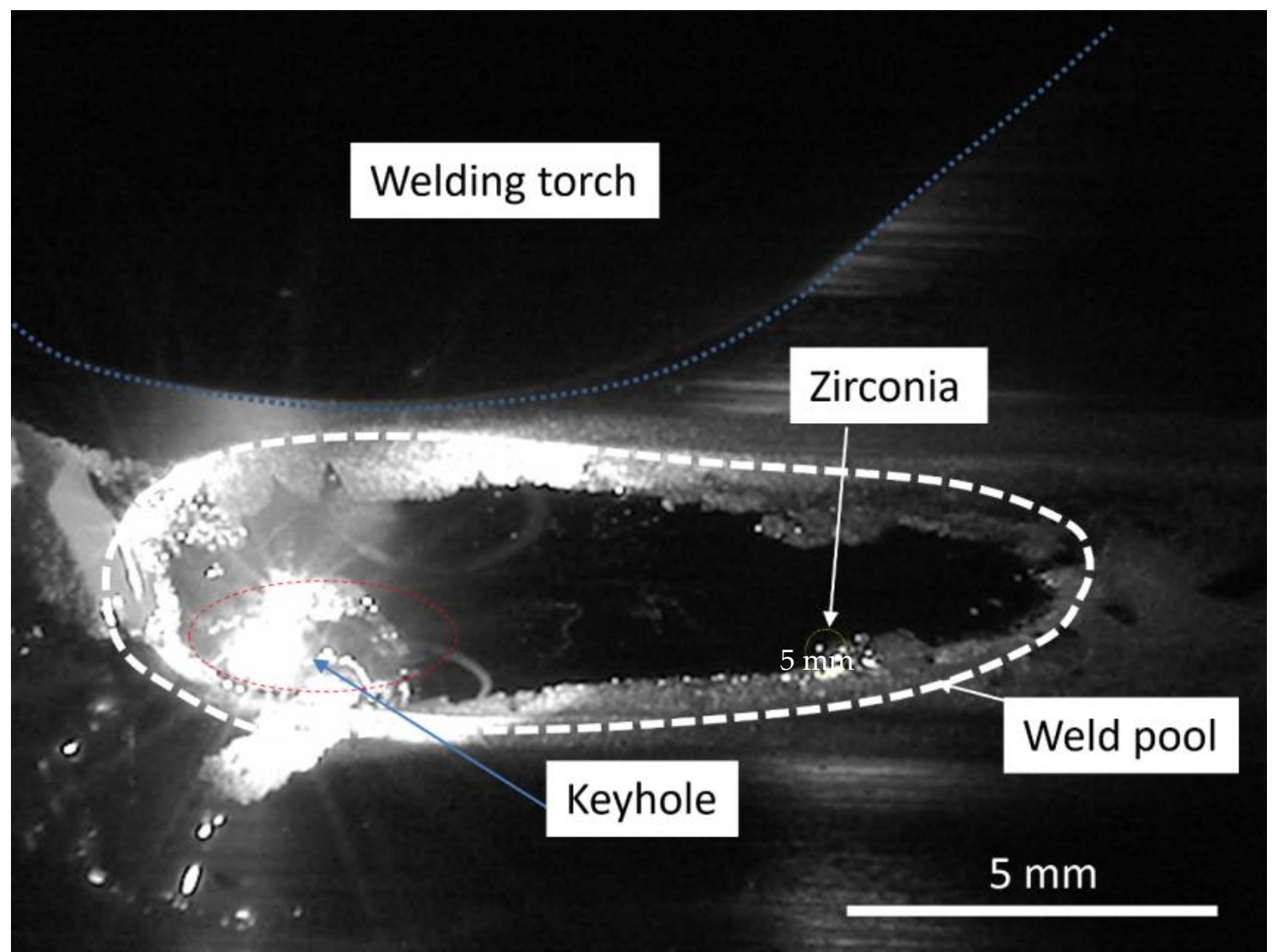

Figure 3. An example of the observation of the weld pool and molten material flow.

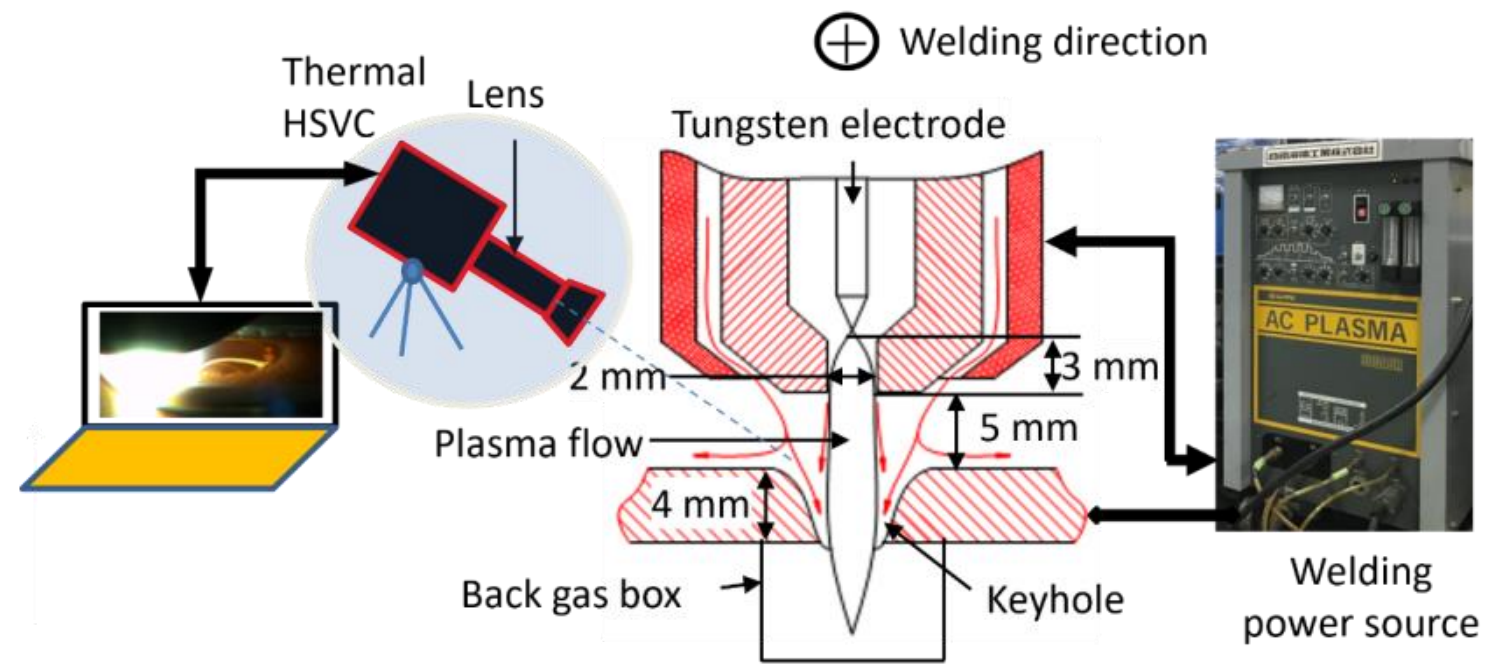

Figure 4. Diagram of temperature measurement on the melted domain surface.

\section{Results and Discussion}

3.1. Welding Bead Formation and Welding Defects

Table 1 displays part of the macrostructure of the weld bead when the welding current was changed at three levels: 80 A, 120 A, and $160 \mathrm{~A}$. It can be seen that there was a clear change of weld bead when current altered from $80 \mathrm{~A}$ to $160 \mathrm{~A}$. Weld bead width on the upper part increased when the current varied, especially when it changed from $120 \mathrm{~A}$ to 160 A. Weld bead width on the lower part also increased when current increased, especially 
when it increased from $120 \mathrm{~A}$ to $160 \mathrm{~A}$. It can be seen that half of total weld seam in the case of $80 \mathrm{~A}$ was without melting on the lower side (blind keyhole status).

Table 1. A part of the cross-section of the weld bead and welding defects.

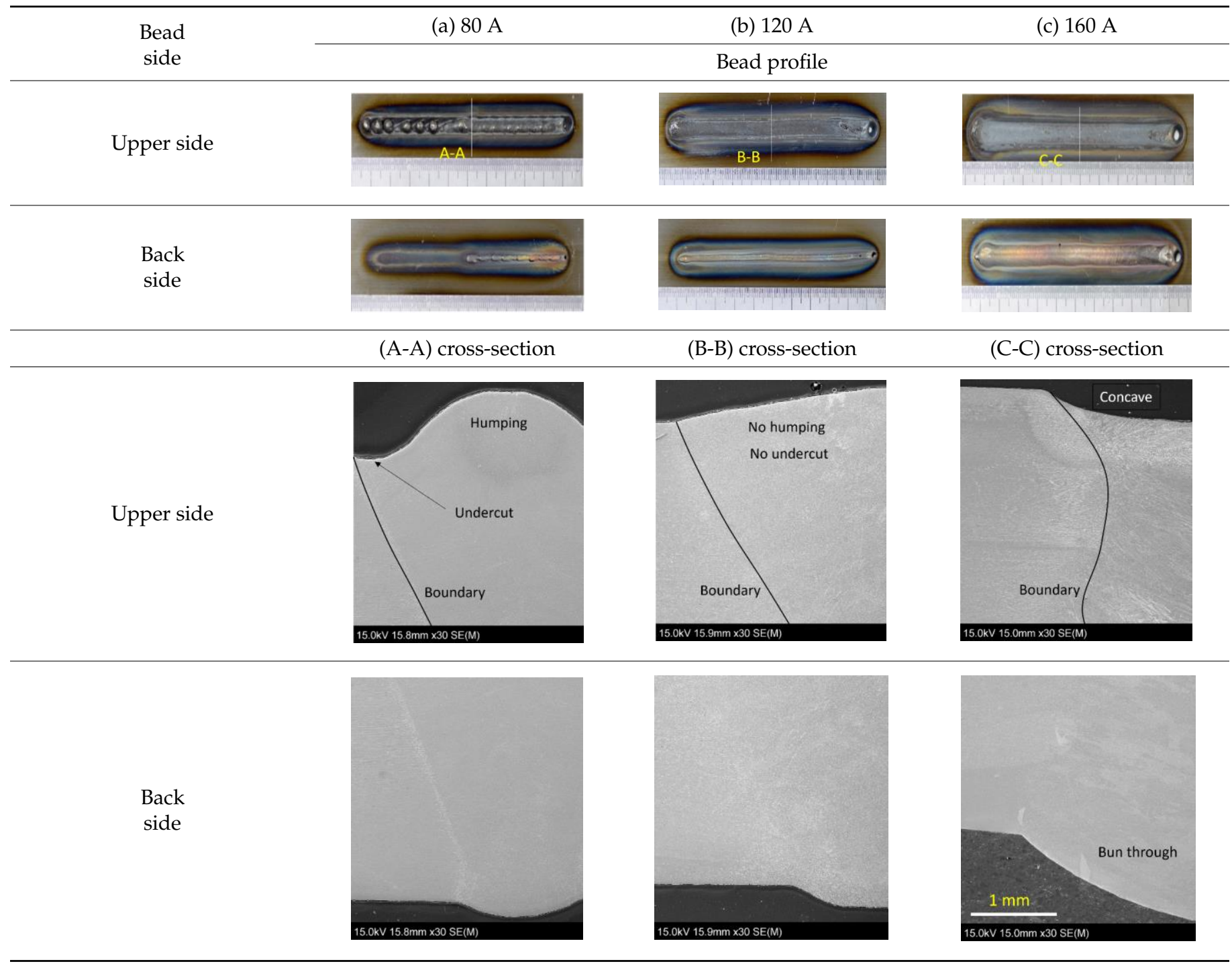

It was measured to confirm that the weld bead on the top side was about $5.0 \mathrm{~mm}$, $6.3 \mathrm{~mm}$, and $7.2 \mathrm{~mm}$ in cases of $80 \mathrm{~A}, 120 \mathrm{~A}$, and $160 \mathrm{~A}$, respectively. The weld bead on the bottom side was about $1.8 \mathrm{~mm}, 2.7 \mathrm{~mm}$, and $6.1 \mathrm{~mm}$, in cases of $80 \mathrm{~A}, 120 \mathrm{~A}$, and $160 \mathrm{~A}$, respectively.

Meanwhile, there were almost no welding defects in the case of $120 \mathrm{~A}$. In this case, the keyhole size was larger than that in the case of $80 \mathrm{~A}$, but it was much smaller than that in the case of $160 \mathrm{~A}$, especially on the lower side. In the case of low welding current (80 A), serious humping and deep undercut at both sides could be seen on the upper side. In addition, it seems that there was not good wettability and the weld bead was unstable on the lower side.

In the case of $160 \mathrm{~A}$, the weld bead was very wide, especially on the bottom surface. The melted domain seemed to sink to the lower side to make a concave on the upper side. On the lower side, a very large bead width could be seen. It could also be seen as the serious excessive convex (burn through) and convex on the lower side. 


\subsection{Temperature on the Melted Domain Surface}

The temperature field on the melted domain surface is presented in Figure 5. In the case of $80 \mathrm{~A}$, the highest temperature zone appeared at $X=5.5 \sim 6.0 \mathrm{~mm}$. From this position toward the keyhole and toward the ending part of the weld pool, the temperature decreased gradually.
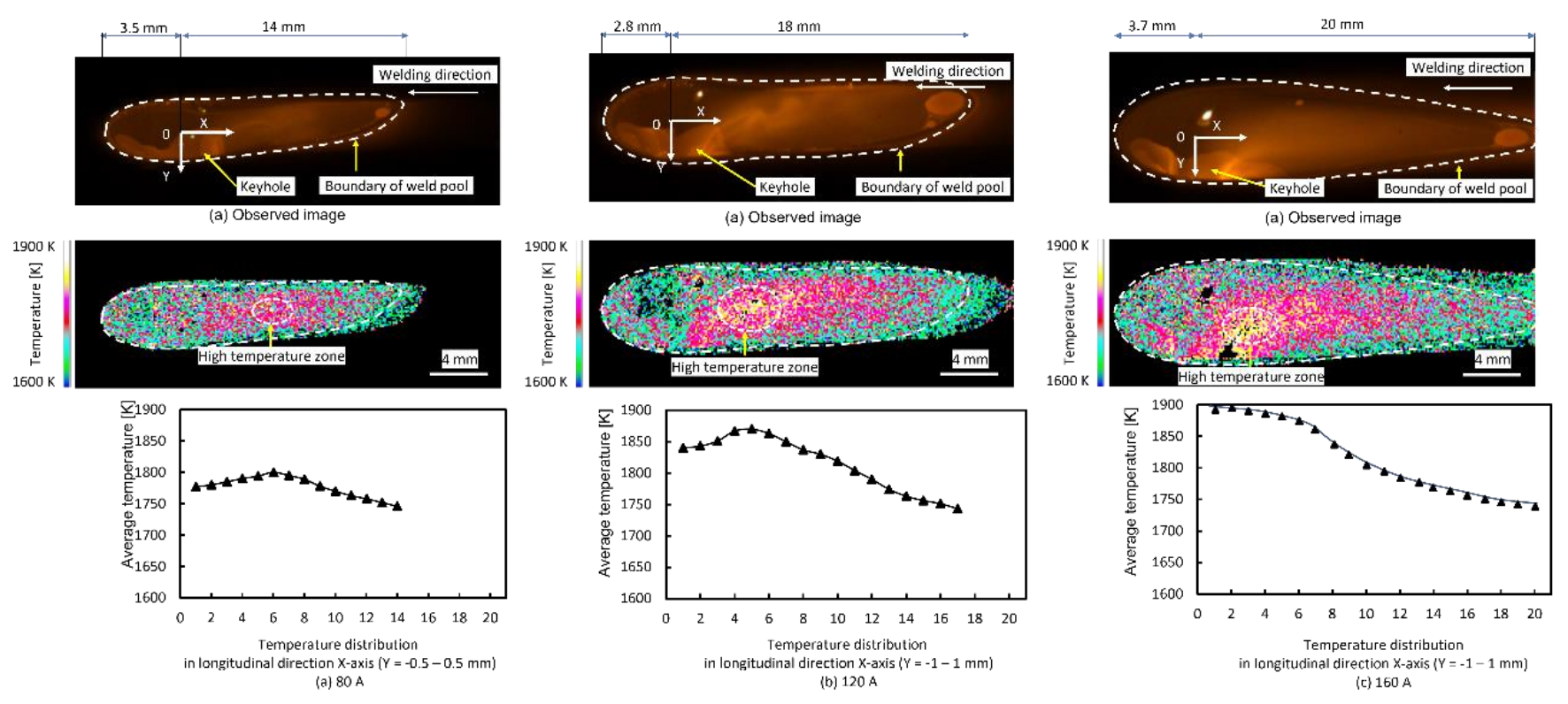

Figure 5. Temperature field on the melted domain surface: (a) for $80 \mathrm{~A}$; (b) for $120 \mathrm{~A}$; and (c) for $160 \mathrm{~A}$.

In the case of $120 \mathrm{~A}$, the highest temperature zone presented at $\mathrm{X}=4.5 \sim 5.5 \mathrm{~mm}$. Similarly, with the case of $80 \mathrm{~A}$, the temperature decreased gradually toward the keyhole and the rear part of the melted domain.

In the case of $160 \mathrm{~A}$, the highest temperature position was located at $X=2.0 \sim 2.5 \mathrm{~mm}$. The temperature slightly reduced from this location toward the keyhole. On the other hand, the temperature was slightly decreased from $X=2.5 \mathrm{~mm}$ until $X=7.0 \mathrm{~mm}$. Afterward, the temperature decreased more sharply from $X=7.0 \mathrm{~mm}$ toward the rear part of the weld pool.

\subsection{Material Flow Dynamic on Molten Pool Surface}

Fluid flow dynamics on the top side of the melted domain are described in Figure 6a-c, corresponding to $80 \mathrm{~A}, 120 \mathrm{~A}$, and $160 \mathrm{~A}$, respectively. In this investigation, the $\mathrm{X}$-axis coincides with the travel line of the torch and Y-axis is perpendicular to that.

In the case of $80 \mathrm{~A}$, particles were moved from the front part of the keyhole toward the rear part of the keyhole. All particles were strongly accelerated in the upward direction from inside the keyhole center toward the top surface behind the keyhole and continuously moved in a backward tendency with gradually decreasing velocity before stopping at the ending region of the melted domain. Most particles were focused on straightly transporting to the rear part of the melted domain. Near the centerline of the melted domain, the velocity of particles was much stronger than that at the sides of the keyhole and melted domain.

In the case of $120 \mathrm{~A}$, it was clearly seen that zirconia particles had an initial slow velocity toward the behind region of the keyhole. From the behind region of the keyhole, there were two ways of particle movement. Several particles near the center line moved in an inward tendency and a downward tendency just behind the keyhole to the bottom surface. Several other particles nearby the keyhole sides accelerated in an upward tendency and moved to the ending region of the melted domain.

In the case of $160 \mathrm{~A}$, there were two places for putting tracer particles, including in front of the keyhole and around the middle region of the melted domain as explained above. 
For particles around the keyhole, similar to cases of $80 \mathrm{~A}$ and $120 \mathrm{~A}$, it started to move from the front part of the keyhole. There was only one convective pattern around the keyhole and two convections around the middle region of the molten pool. For mostly particles around the keyhole, they run in a downward tendency with a high velocity. However, particles put on the weld pool from particle supply system near the middle part of weld pool moved in two ways: (1) backward and outward tendencies toward the end part of weld pool and (2) frontward and outward tendencies toward the keyhole before entering the keyhole center. In addition, several other particles around the keyhole moved in an outward tendency at the front part of the keyhole before moving at an inward tendency and a downward tendency at the rear part of the keyhole.

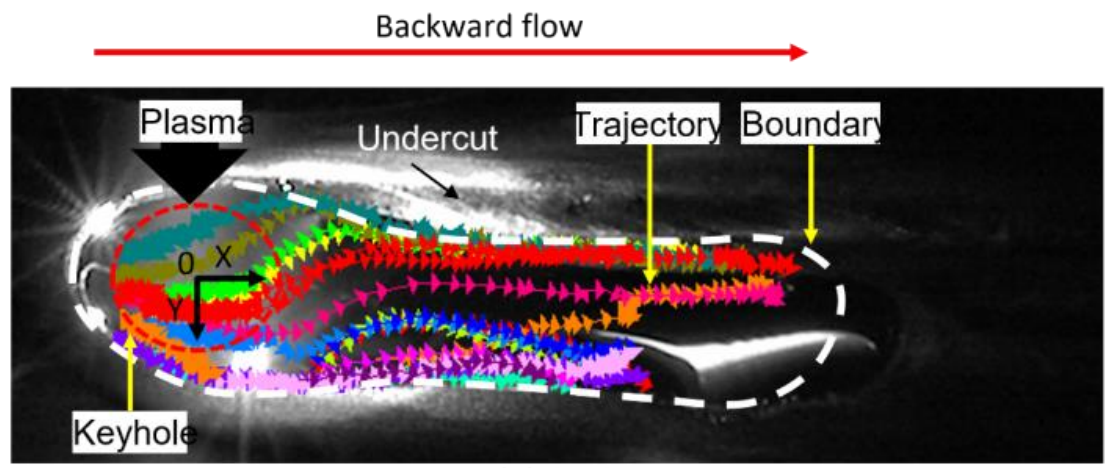

(a) $80 \mathrm{~A}$

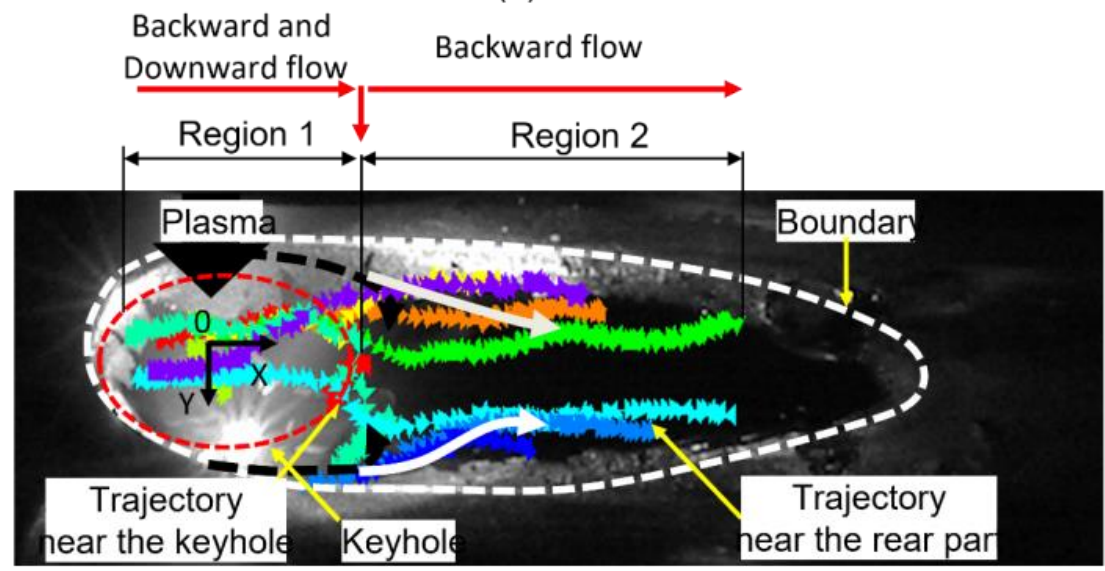

(b) $120 \mathrm{~A}$

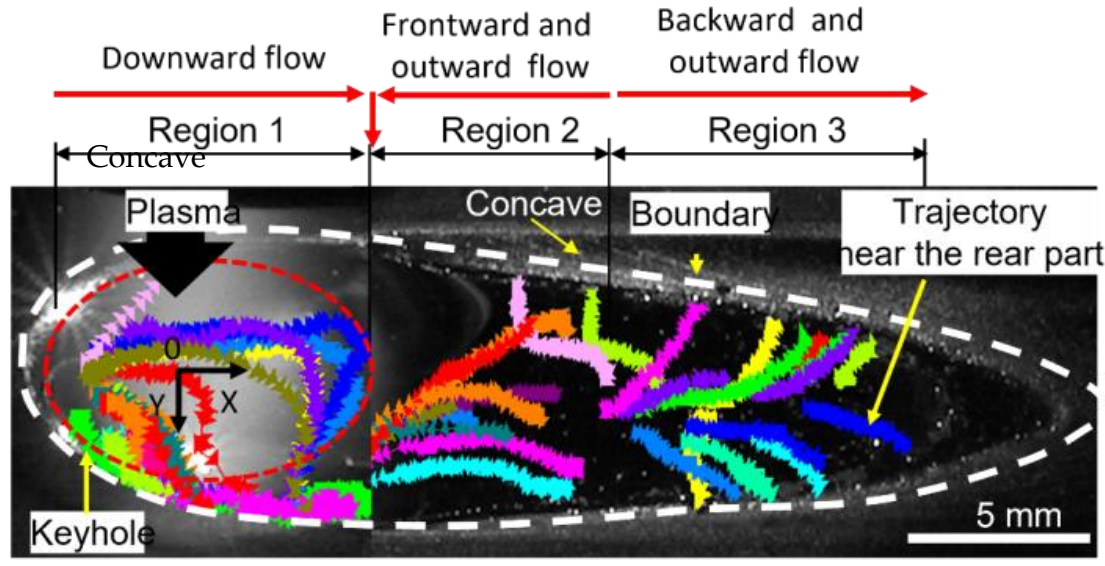

(c) $160 \mathrm{~A}$

Figure 6. Material flow dynamic on the melted domain surface: (a) for $80 \mathrm{~A}$; (b) for $120 \mathrm{~A}$; and (c) for $160 \mathrm{~A}$. 
The weld pool length was about $14 \mathrm{~mm}, 16 \mathrm{~mm}$, and $23 \mathrm{~mm}$ in the cases of $80 \mathrm{~A}, 120 \mathrm{~A}$, and $160 \mathrm{~A}$, respectively. Meanwhile, its width was about $5.0 \mathrm{~mm}, 6.2 \mathrm{~mm}$, and $7.1 \mathrm{~mm}$ in the cases of $80 \mathrm{~A}, 120 \mathrm{~A}$, and $160 \mathrm{~A}$, respectively. It can be also seen there was an undercut in the case of $80 \mathrm{~A}$, and concave on top surface in the case of $160 \mathrm{~A}$.

\subsection{Velocity of Material Flow on the Melted Domain Surface}

In this subsection, the flow velocity is analyzed in detail. In order to discuss the velocity distribution on the melted domain surfaces, the velocity was considered at several longitudinal sections along the $\mathrm{X}$-axis.

The melted pool width was largest in the case of $160 \mathrm{~A}$, and smallest in the case of $80 \mathrm{~A}$. As a result, the number of longitudinal sections were different in all cases. They were six longitudinal-sections (160 A), five longitudinal-sections (120 A), and four longitudinalsections $(80 \mathrm{~A})$. On the other hand, due to the very long weld pool in the case of $160 \mathrm{~A}$, the velocity graph was divided two domains according to the HSVC setting position change. One of them is around keyhole zone, and another one is from the middle part until the ending part of the weld pool.

The flow velocity field on the upper side around the keyhole in the case of $160 \mathrm{~A}$ is described in Figure 7. The velocity increased before it gradually decreased. However, at only $\mathrm{Y}=-3 \sim-1 \mathrm{~mm}$, the velocity decreased from $\mathrm{X}=2$ until $\mathrm{X}=6 \mathrm{~mm}$. In other cases, the velocity of molten material flow generally increased firstly, before it decreased from $X=5.0 \sim 6.0 \mathrm{~mm}$. For the backward convection pattern, the maximal velocity was about $0.98 \mathrm{~ms}^{-1}$ at $\mathrm{X}=0.0 \mathrm{~mm}$. Meanwhile the maximal velocity of downward convection pattern was about $1.12 \mathrm{~ms}^{-1}$ at $X=5.5 \mathrm{~mm}$.
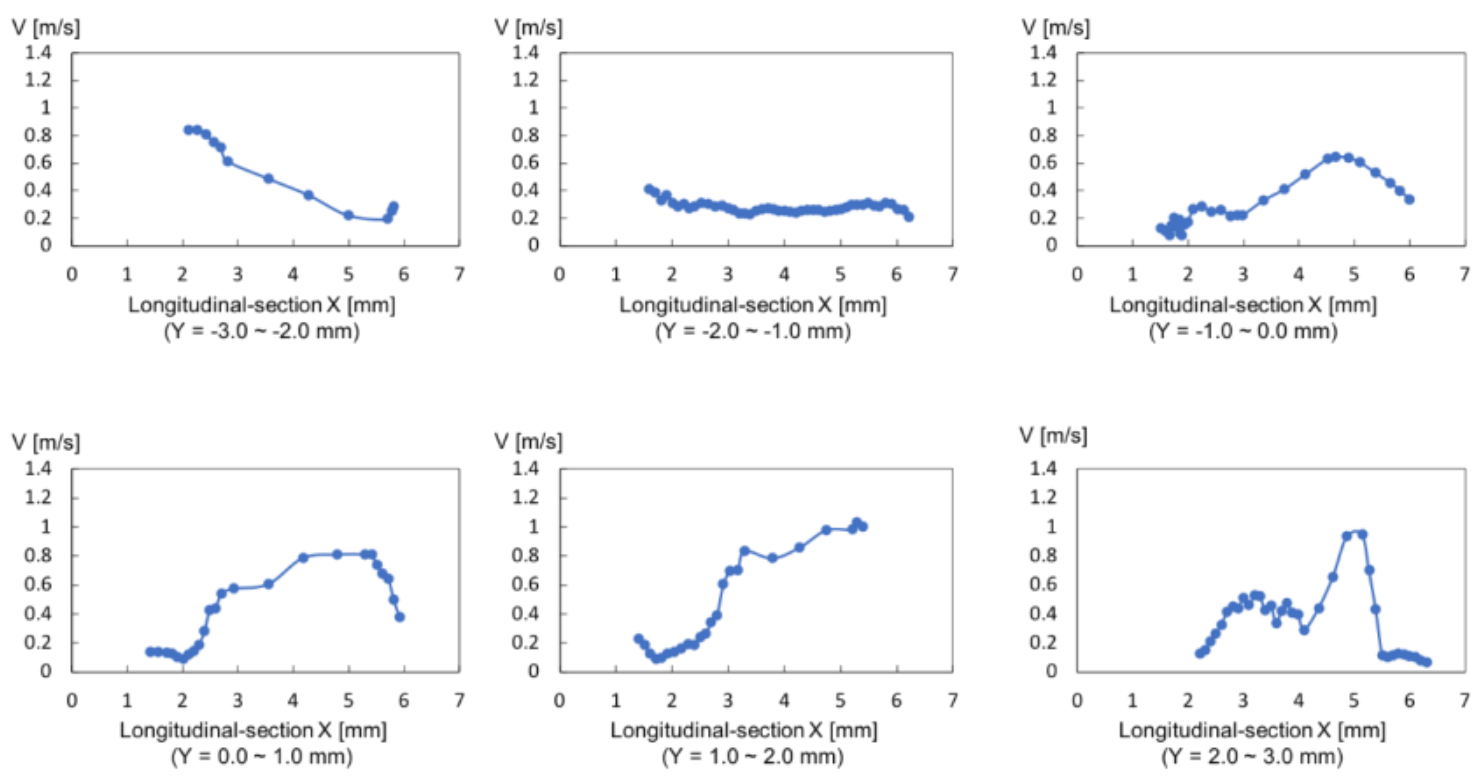

Figure 7. Flow velocity graph around the keyhole in the case of $160 \mathrm{~A}$.

Distribution of flow velocity around the ending part $(X=7.0 \sim 23.0 \mathrm{~mm})$ in the case of $160 \mathrm{~A}$ is shown in Figure 8. The velocity increased from the ending part of the melted domain toward the keyhole, especially around $X=7 \sim 8 \mathrm{~mm}$. At $X=7 \mathrm{~mm}$, the velocity was very high. This is caused by the inward flow from the ending part of the weld pool until the keyhole and in downward flow from the upper side toward the lower side of the melted region. At $Y=-3.0 \sim-2.0 \mathrm{~mm}$ region, the velocity was mostly unchanged along the weld pool surface. This case can be explained because the tracer particle was detected just within $X=12 \sim 16.5 \mathrm{~mm}$. In this area, the frontward movement of tracer particles is stable with low velocity. The maximal velocity was about $1.2 \mathrm{~ms}^{-1}$ at $X=8.0 \mathrm{~mm}$ in the case of $\mathrm{Y}=1.0 \sim 2.0 \mathrm{~mm}$. The minimal velocity was about $0.15 \mathrm{~ms}^{-1}$ at $\mathrm{X}=18.8 \mathrm{~mm}$ in the case of $\mathrm{Y}=-1.0 \sim 0.0 \mathrm{~mm}$. 

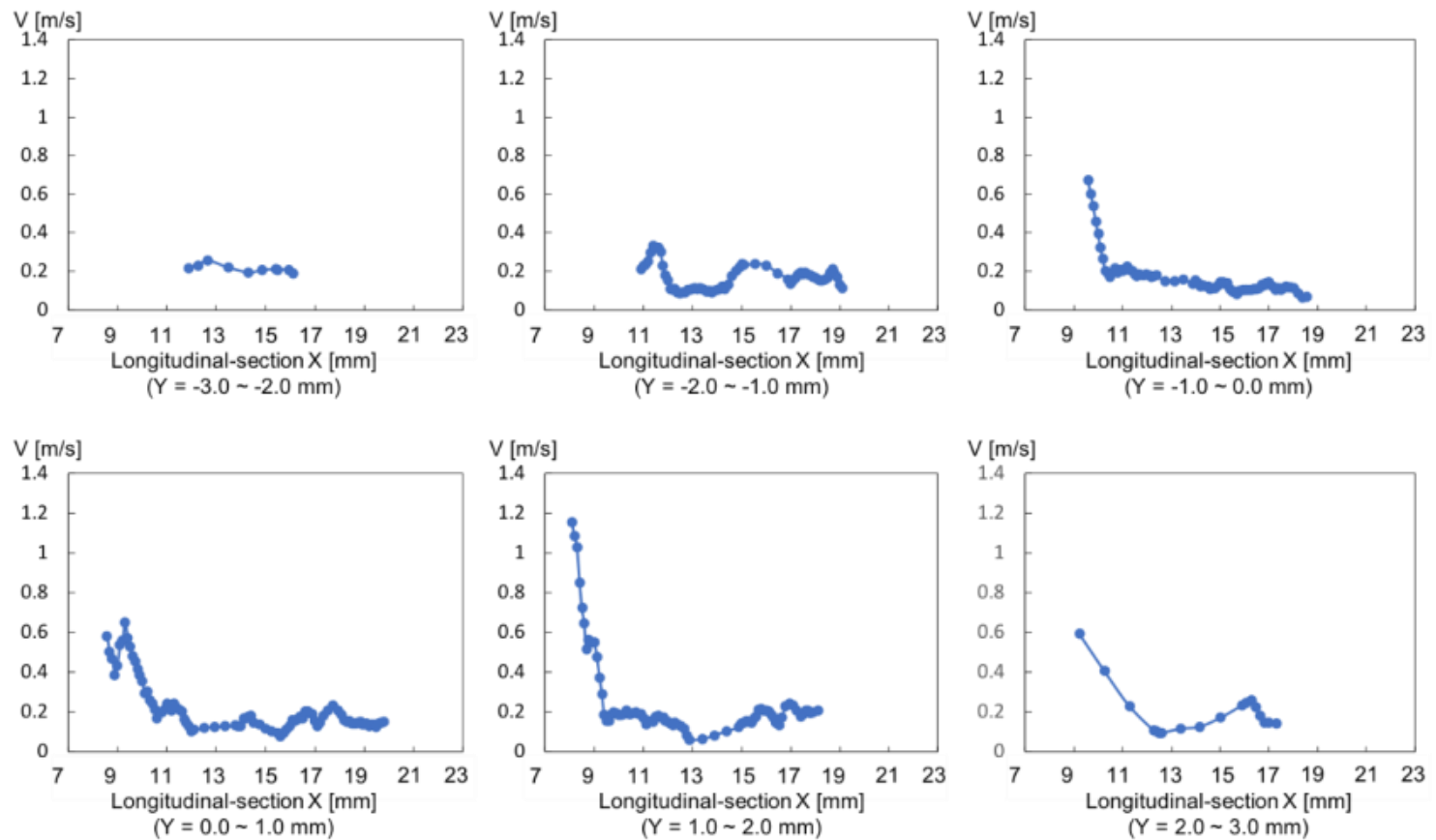

Figure 8. Flow velocity graph around the ending part in the case of $160 \mathrm{~A}$.

The velocity distribution on the upper side in the case of $120 \mathrm{~A}$ is exhibited in Figure 9. In this case, the velocity increased from $X=0.0 \sim 6.0 \mathrm{~mm}$, and then decreased from $X=6.0$ until the ending part of the weld pool $(X=15 \mathrm{~mm})$. As indicated in Figure 6 , there were two convective patterns in the case of $120 \mathrm{~A}$. As a result, it can be considered that the convection flow around the keyhole in inward-backward-downward directions matched with the increased velocity area $(X=2.0 \sim 6.0 \mathrm{~mm})$. Additionally, the convection flow from the middle part until the ending part of the melted domain corresponded to the decreased velocity area from $X=6.0 \sim 15.0 \mathrm{~mm}$. The maximal velocity was about $0.89 \mathrm{~ms}^{-1}$ at $X=6.0 \mathrm{~mm}$ in the case of $Y=0.0 \sim 1.0 \mathrm{~mm}$. The velocity at the ending part of the weld pool was about $0.19 \mathrm{~ms}^{-1}$ at $X=14.5 \mathrm{~mm}$.
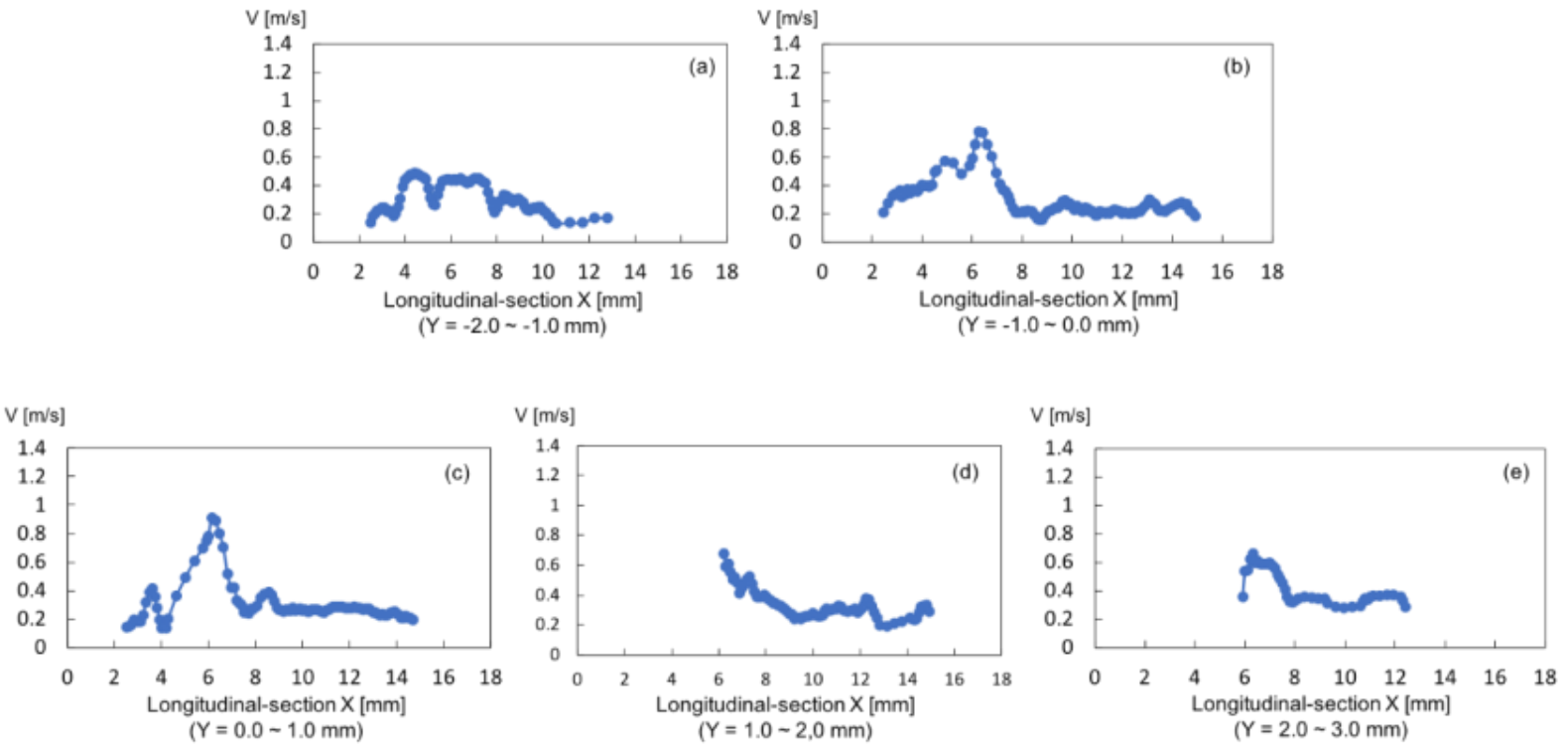

Figure 9. Flow velocity graph in the case of $120 \mathrm{~A}$. 
The velocity in the case of $80 \mathrm{~A}$ is described in Figure 10. In this case, the velocity increased sharply from $X=2.0 \mathrm{~mm}$ until $X=6.0 \mathrm{~mm}$. Then, the velocity rapidly decreased with $X=6.0 \sim 8.0 \mathrm{~mm}$. After that, the velocity moderately deducted until the ending part of the melted region. The velocity reached the maximal value of $1.4 \mathrm{~ms}^{-1}$ at $X=6.0 \mathrm{~mm}$ in the case of $Y=1.0 \sim 2.0 \mathrm{~mm}$. The velocity was about $0.15 \mathrm{~ms}^{-1}$ at the keyhole wall. The velocity at the ending part of the molten pool was $0.25 \mathrm{~ms}^{-1}$ at $X=11.7 \mathrm{~mm}$ in the case of $\mathrm{Y}=1.0 \sim 2.0 \mathrm{~mm}$.
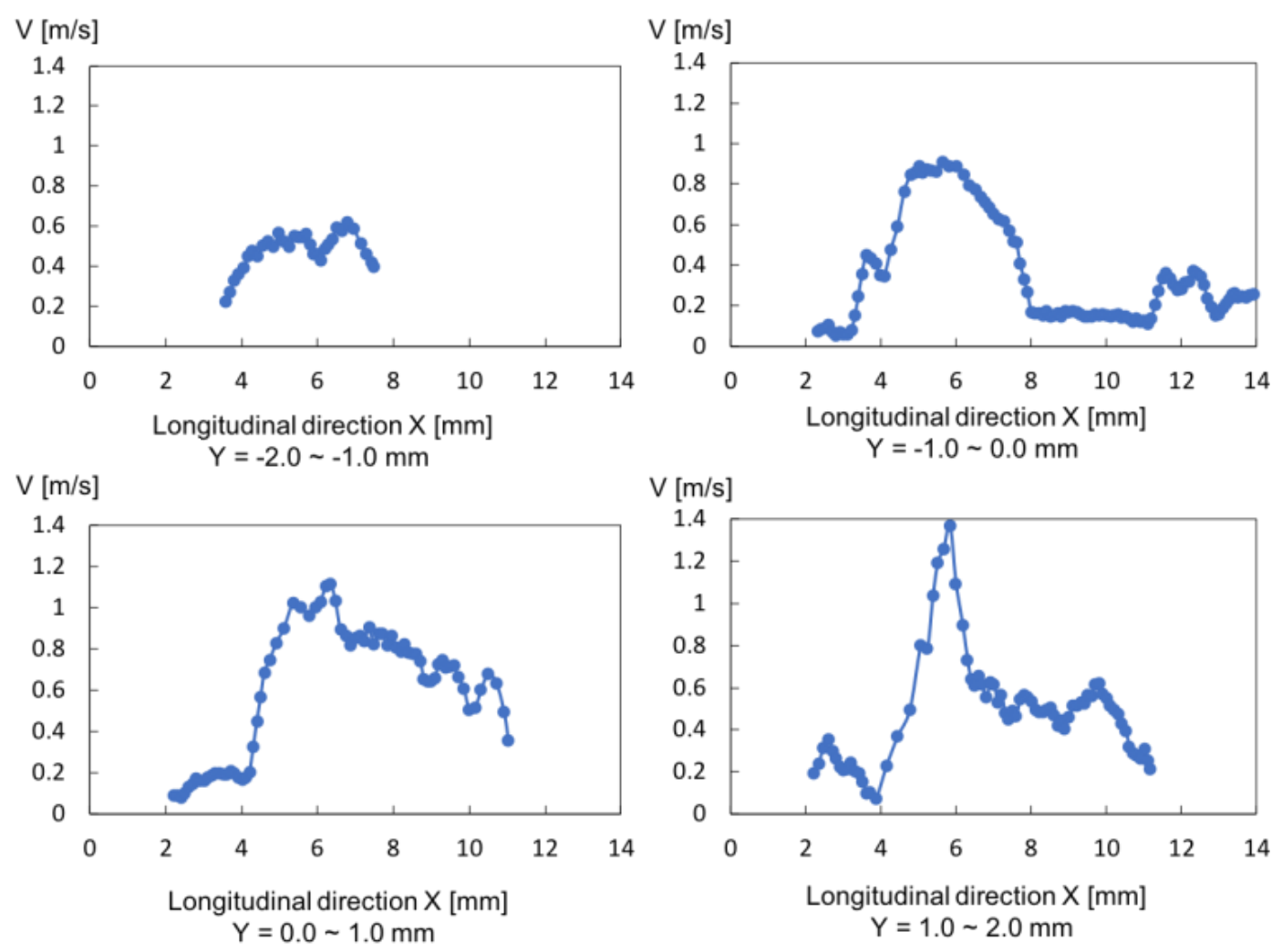

Figure 10. Flow velocity graph in the case of $80 \mathrm{~A}$.

\subsection{Discussion}

To consider the relationship among welding defects with convection and the material flow dynamic, a discussion can be opened as follows.

In the case of $80 \mathrm{~A}$, the particles directly moved with high velocity toward the ending region of the melted domain.

Meanwhile, in the case of $120 \mathrm{~A}$, the particles behind the keyhole had two movement trends including: backward and downward directions around the weld pool center (particles at weld pool center) and backwards toward the ending region of the melted domain (particles at side weld pool). Furthermore, in this case, the velocity was less than that in comparison with the case of $80 \mathrm{~A}$.

In the case of $160 \mathrm{~A}$, the particles at the behind half part of the weld pool moved with trends in outward and backward directions toward the side weld pool, rather than being transported directly to the rear part of the melted domain. Meanwhile, the particles at the front half part of the weld pool tended to move in frontward and downward directions. On the other hand, particles around the keyhole were transported with the downward direction along the keyhole wall. In this case, the velocity was higher than that in the case of $120 \mathrm{~A}$ but it was lower than that in the case of $80 \mathrm{~A}$.

On the other hand, as aforementioned above, because of very low heat input in the case of $80 \mathrm{~A}$, at first the blind keyhole status was formed within the front half part of the welding seam (see Table 1a). During this period, the heat input grew rapidly due to heat 
transfer from the torch toward the keyhole, and weld pool in the downward direction to form the opening keyhole status at the behind half part of the weld seam (see Table 1a). However, this status is unstable and the weld bead on the lower side was unstabilized. On the other hand, in a recent publication, it was discussed that in the case of small keyhole diameter (low welding current), the plasma flow was mainly in the reverse direction from the middle region of the keyhole toward the upper side of the melted domain [26]. In other papers, it was analyzed that plasma flow and arc pressure were the dominant driving forces for the convection and heat transportation in the PAW process, rather than Marangoni force $[19,28]$. This means that the heat is dominantly transported in the upward direction with high speed under the control of plasma flow and arc pressure. From these results, it can be considered that the deep undercut and serious humping phenomena on the top surface as seen in Table 1a and Figure 6a in the case of $80 \mathrm{~A}$ was mainly related to the high velocity and straight movement of particles toward the ending part of the melted domain with the same mechanism as in refs $[29,30]$.

When current is $120 \mathrm{~A}$, the increased heat input was supported to the melted domain in order to create an opening keyhole status immediately after starting the arc. In this case, the plasma flow and the arc pressure were allocated in both directions: upwards along the top side and downwards alongside the keyhole wall [26]. The balance of the heat input on both the lower side and the upper side is suitable to procedure a weld seam with no undercut and humping defects on the top surface and no excessive convex (burn-through) on the bottom surface (see Table 1b).

In the case of high welding current $(160 \mathrm{~A})$, the heat input under influence of the arc pressure and the plasma flow on the keyhole profile (very large diameter and small wall inclination) was much increased, a very large pool volume and a wide keyhole contour as can be seen in Table 1c and Figure 6c [14]. The plasma flow and the arc pressure were almost pushed down. The heat input was concentrated mainly on the lower surface. This formed a very wide weld bead and an enormous weldment volume (excessive convex) especially on the lower side. In addition, in a recent paper [26], the authors discussed the molten material flow behavior inside the melted domain, and the results showed that the material flow inside the melted domain is diverted at $X=3.5 \sim 4.5 \mathrm{~mm}$ in the case of $160 \mathrm{~A}$ (from upwards to frontwards), at $\mathrm{X}=5.0 \sim 6.0 \mathrm{~mm}$ in the case of $120 \mathrm{~A}$ (from backwards to downwards), and at $X=6.0 \sim 7.0 \mathrm{~mm}$ in the case of $80 \mathrm{~A}$ (from backwards to downwards). On the other hand, the authors also measured the flow velocity inside the weld pool. The maximal velocity was about $0.34 \mathrm{~ms}^{-1}$ in the case of $160 \mathrm{~A}$. This maximal velocity occurs at the keyhole bottom surface (nearby keyhole). Meanwhile, the maximal velocity was $0.40 \mathrm{~ms}^{-1}$, occurring at the keyhole top surface in the case of $80 \mathrm{~A}$ (nearby keyhole). This change (velocity was increased when the current was low and in contrast) had a similar tendency as with the velocity change on the melted domain surface in this paper, in which the velocity in the case of $160 \mathrm{~A}$ was lower than the case of $80 \mathrm{~A}$, but was higher than the case of $120 \mathrm{~A}$. Furthermore, from ref [26] and the results in this paper, it can be considered that maximal velocity values inside the melted domain were lower in comparison to the maximal velocity on the melted domain surface at the same region. Meanwhile, the convection pattern tended to outward and backward directions at the behind half part in the case of high welding current $(160 \mathrm{~A})$ caused a very large and long weld pool. Furthermore, the convection flow in the downward direction around the keyhole resulted in a large heat input amount pushing down to the bottom surface [31]. This is directly related to the excessive convex phenomenon on the lower side and the concave on the upper side of the melted domain.

In order to explain the behavior of material flow and convection patterns under the activity of driving forces, an underlying consideration was performed.

As found out in recent papers [19,27], the driving forces in PAW process are shear force (plasma flow and arc pressure) and Marangoni force. Meanwhile, the buoyancy force and electromagnetic force are not large enough to control the material flow and convection patterns in the PAW process. The shear force is created by two components: upward 
direction at the upper side of the melted domain and downward direction alongside the keyhole.

In the case of low welding current $(80 \mathrm{~A})$, the highest temperature zone was located at the weld pool center alongside from the keyhole center, about $5.5 \mathrm{~mm}$ (at $X=5.5 \mathrm{~mm}$ ). In this case, if considering only Marangoni force influence, the convection flows must be from the high temperature zone toward the low temperature zone. In other words, the material flow must be from the weld pool center toward the weld pool side, the keyhole, and the rear part of the weld pool. However, as seen in Figure 6a, the fluid flows were mostly transported in the backward direction from the keyhole. Furthermore, the shear force in this case was mostly in upward and backward directions as explained above and in ref [26]. It means that the shear force component in upward direction was stronger than the Marangoni force. The convection flow was controlled mainly by a strong shear force and the Marangoni force in opposite directions. In this case, shear force is the main dominant force.

In the case of $120 \mathrm{~A}$, a similar situation with the above case can be seen. The highest temperature zone was at $X=4.5 \mathrm{~mm}$. Under the activity of the Marangoni force, the convection flow should be from this zone toward the side, the keyhole, and the rear part of the weld pool (high temperature toward low temperature). However, from Figure $6 \mathrm{~b}$ it can be seen that one convection flow was downward around the keyhole, and another one was transferred straight to the rear part of the weld pool. It means that around the keyhole, the convection flow was controlled by a weak shear force component and a Marangoni force in opposite directions. As a result, the material flow was in a downward direction. In this case, the Marangoni force was the main dominant force. For the convection flow toward the rear part of the weld pool, the shear force and Marangoni force were in the same, backward direction. Furthermore, the shear force component in the upward direction was weaker in comparison with the case of $80 \mathrm{~A}$, so the particle velocity was smaller.

In the case of $160 \mathrm{~A}$, the keyhole size became very large and more straight from the top side toward the bottom side. As a result, the share force component in the downward direction was much stronger than the share force component in upward direction [26]. On the other hand, the highest temperature zone was at around $X=2.5 \mathrm{~mm}$. Furthermore, the temperature slightly decreased from $X=2.5 \mathrm{~mm}$ until $X=6.0 \mathrm{~mm}$. After that, the temperature decreased more sharply from $X=6.5 \mathrm{~mm}$ until the rear part of the weld pool. In this case, under the activity of Marangoni force, the convection flow should be in the frontward direction toward the keyhole, the backward direction toward the end part of the weld pool, and the outward direction to the side of the weld pool from the high-temperature zone. However, as seen in Figure $6 c$, the convection flow was frontward at region 1, frontward in region 2, and backward in region 3. So, in this case, the convection flow around the keyhole was controlled by a very strong shear force component in the downward direction and the frontward direction Marangoni force. The convection flow in the frontward direction in region 2 was controlled by a very weak Marangoni force (due to the slight change of temperature at this region) in the backward direction and a strong shear force component in the downward direction. Additionally, the convection flow in the backward direction at region 3 was controlled mainly by Marangoni force in the backward direction and very weak shear force component in backward direction. Furthermore, due to the very strong shear force component in the downward direction around the keyhole, the tracer particle's velocity was much higher than that in the case of $120 \mathrm{~A}$.

In summary, the shear force due to the plasma flow and arc pressure was changed depending on the keyhole contour. Then, the share force components in the upward or downward directions became stronger or weaker. The Marangoni force was changed with the variation of the temperature distribution. It became stronger when the temperature was reduced largely and in contrast it became weaker when the temperature was reduced slightly in the same distance scale. The interaction between shear force and the Marangoni force principally controlled the convection patterns change in PAW process. 


\section{Conclusions}

In this paper, weld beads, material flow, velocity, and temperature on melted domain surface in relation to welding defects were discussed in detail. Several main conclusions are as follows:

1. No welding defects were seen in the case of $120 \mathrm{~A}$, but serious humping and undercut phenomena was observed in the case of $80 \mathrm{~A}$. Meanwhile, concave and convex occurred in the case of $160 \mathrm{~A}$.

2. The welding defects (undercut and humping) related to a high-speed fluid flow on the surface of the melted domain in the case of $80 \mathrm{~A}$.

3. The excessive convex and concave on the bottom surface was with a reverse fluid flow in the downward direction around the keyhole in the case of $160 \mathrm{~A}$.

4. The convection speed was faster in the case of low welding current (80 A). Meanwhile, the slower speed occurred in the case of high welding current (160 A).

5. The interaction between shear force and Marangoni force mainly controlled the convection and heat transportation in the weld pool.

Author Contributions: H.L.N.: experiment, data analysis, writing-revision; A.V.N.: conceptualization, methodology, writing-revision, supervision; H.L.D.: experiment, data analysis, writingrevision; T.-H.N.: facilities, discussion; S.T.: supervision, discussion; M.T.: supervision, discussion, facilities. All authors have read and agreed to the published version of the manuscript.

Funding: This investigation was funded by Ho Chi Minh City (HCMUT) under grant number To-CK-2020-01.

Data Availability Statement: Data can be available based on the requirements to verify this work.

Acknowledgments: The authors acknowledge Murata at Murata Welding Laboratory for encouraging to do this work. Authors acknowledge also Trinh Quang Ngoc from Osaka University for the support during a part of experiments. We would also like to thank HCMUT, VNU-HCM for the support of time and facilities for this work.

Conflicts of Interest: The authors declare no conflict of interest.

\section{References}

1. Zhao, C.; Parab, N.D.; Li, X.; Fezzaa, K.; Tan, W.; Rollett, A.D.; Sun, T. Critical instability at moving keyhole tip generates porosity in laser melting. Science 2020, 370, 1080-1086. [CrossRef] [PubMed]

2. Yakout, M.; Phillips, I.; Elbestawi, M.; Fang, Q. In-situ monitoring and detection of spatter agglomeration and delamination during laser-based powder bed fusion of Invar 36. Opt. Laser Technol. 2021, 136, 106741. [CrossRef]

3. Zong, R.; Chen, J.; Wu, C.S.; Padhy, G.K. Influence of molten metal flow on undercutting formation in GMAW. Sci. Technol. Weld. Join. 2016, 22, 198-207. [CrossRef]

4. Nguyen, T.C.; Weckman, D.C.; Johnson, D.A.; Kerr, H.W. The humping phenomenon during high speed gas metal arc welding. Sci. Technol. Weld. Join. 2005, 10, 447-459. [CrossRef]

5. Chen, Y.; Clark, S.J.; Leung, C.L.A.; Sinclair, L.; Marussi, S.; Olbinado, M.P.; Boller, E.; Rack, A.; Todd, I.; Lee, P.D. In-situ Synchrotron imaging of keyhole mode multi-layer laser powder bed fusion additive manufacturing. Appl. Mater. Today 2020, 20, 100650. [CrossRef]

6. Yousuke, K.; Kouki, N.; Yosuke, U.; Masami, M.; Kouji, N.; Horoshi, K.; Seiji, K. Relationship between melt flows based on three-dimensional X-ray transmission in-situ observation and spatter reduction by angle of incidence and defocusing distance in high-power laser welding of stainless steel. Q. J. Jpn. Weld. Soc. 2016, 34, 239-248.

7. Kawahito, Y.; Wang, H. In-situ observation of gap filling in laser butt welding. Scr. Mater. 2018, 154, 73-77. [CrossRef]

8. Morisada, Y.; Fujii, H.; Kawahito, Y.; Nakata, K.; Tanaka, M. Three-dimensinal visualization of material flow during friction stir welding by two pairs of X-ray transmission system. Scipta Mater. 2011, 65, 1085-1088. [CrossRef]

9. Aucott, L.; Dong, H.; Mirihanage, W.; Atwood, R.; Kidess, A.; Gao, S.; Wen, S.; Marsden, J.; Feng, S.; Tong, M.; et al. Revealing internal flow behaviour in arc welding and additive manufacturing of metals. Nat. Commun. 2018, 9, 1-7. [CrossRef]

10. Chen, Y.; Clark, S.J.; Huang, Y.; Sinclair, L.; Leung, C.L.A.; Marussi, S.; Connolley, T.; Magdysyuk, O.V.; Atwood, R.C.; Baxter, G.J.; et al. In situ X-ray quantification of melt pool behaviour during directed energy deposition additive manufacturing of stainless steel. Mater. Lett. 2021, 286, 129205. [CrossRef]

11. Cunningham, R.; Zhao, C.; Parab, N.; Kantzos, C.; Pauza, J.; Fezzaa, K.; Sun, T.; Rollett, A.D. Keyhole threshold and morphology in laser melting revealed by ultrahigh-speed x-ray imaging. Science 2019, 363, 849-852. [CrossRef] 
12. Guo, Q.; Zhao, C.; Qu, M.; Xiong, L.; Hojjatzadeh, S.M.H.; Escano, L.I.; Parab, N.D.; Fezzaa, K.; Sun, T.; Chen, L. In-situ full-field mapping of melt flow dynamics in laser metal additive manufacturing. Addit. Manuf. 2020, 31, 100939. [CrossRef]

13. Miyagi, M.; Wang, J. Keyhole dynamics and morphology visualized by in-situ X-ray imaging in laser melting of austenitic stainless steel. J. Mater. Process. Technol. 2020, 282, 116673. [CrossRef]

14. Xu, B.; Chen, S.; Tashiro, S.; Jiang, F.; Tanaka, M. Physical mechanism of material flow in variable polarity plasma arc keyhole welding revealed by in situ x-ray imaging. Phys. Fluids 2021, 33, 017121. [CrossRef]

15. van Anh, N.; Tashiro, S.; van Hanh, B.; Tanaka, M. Influence of plasma gas on the behavior of convention flow on weld pool surface. Q. J. Jpn. Weld. Soc. 2017, 35, 98s-102s.

16. van Anh, N.; Manh, N.H.; Tashiro, S.; Tanaka, M. Behavior of keyhole exit during the cutting arc period. Mater. Eng. Forum 2018, $26,92-97$.

17. Wu, D.; Tashiro, S.; Hua, X.; Tanaka, M. A novel electrode-arc-weld pool model for studying the keyhole formation in the keyhole plasma arc welding process. J. Phys. D Appl. Phys. 2019, 52, 165203. [CrossRef]

18. Xu, B.; Chen, S.; Tashiro, S.; Jiang, F.; Nguyễn, V.A.; Tanaka, M. Material flow analyses of high-efficiency joint process in VPPA keyhole flat welding by X-ray transmission system. J. Clean. Prod. 2020, 250, 119450. [CrossRef]

19. Huu, M.N.; Van, A.N.; Van, T.N.; Hai, D.T.; Van, T.N.; Tien, D.N.; Nguyen, T.-H. Material Flow Behavior on Weld Pool Surface in Plasma Arc Welding Process Considering Dominant Driving Forces. Appl. Sci. 2020, 10, 3569. [CrossRef]

20. Shu, Y.F.; Rubinsky, B. Two-dimensional heat transfer study on the keyhole plasma arc welding process. Int. J. Heat Mass Transfer. 1988, 31, 1409-1421.

21. Keanini, R.G.; Rubinsky, B. Three-dimensional simulation of the plasma arc welding process. Int. J. Heat Mass Transfer. 1993, 36, 3283-3298. [CrossRef]

22. Jian, X.; Wu, C.S. Numerical analysis of the coupled arc-weld pool-keyhole behaviors in stationary plasma arc welding. Int. J. Heat Mass Transfer. 2015, 84, 839-847. [CrossRef]

23. Li, Y.; Feng, Y.; Li, Y.; Zhang, X.; Wu, C. Plasma arc and weld pool coupled modeling of transport phenomena in keyhole welding. Int. J. Heat Mass Transf. 2016, 92, 628-638. [CrossRef]

24. Pan, J.; Hu, S.; Yang, L.; Chen, S. Numerical analysis of the heat transfer and material flow during keyhole plasma arc welding using a fully coupled tungsten-plasma-anode model. Acta Mater. 2016, 118, 221-229. [CrossRef]

25. Tanaka, M.; Lowke, J.J. Predictions of weld pool profiles using plasma physics. J. Phys. D Appl. Phys. 2007, 40, R1. [CrossRef]

26. van Anh, N.; Tashiro, S.; Manh, N.H.; van Hanh, B.; Tanaka, M. Effect of the eddies formed inside a weld pool on welding defects during plasma keyhole arc welding. J. Manuf. Process. 2020, 59, 649-657.

27. Van Anh, N.; Tashiro, S.; Van Hanh, B.; Tanaka, M. Experimental investigation on the weld pool formation process in plasma keyhole arc welding. J. Phys. D Appl. Phys. 2018, 51, 015204. [CrossRef]

28. Van Anh, N.; Wu, D.S.; Tashiro, S.; Tanaka, M. Undercut formation mechanism in the keyhole plasma arc welding. Weld. J. 2019, 98, 204-212.

29. Norman, P.M.; Karlsson, J.; Kaplan, A.F.H. Mechanisms Forming Undercuts during Laser Hybrid Arc Welding. Phys. Procedia 2011, 12, 201-207. [CrossRef]

30. Zong, R.; Chen, J.; Wu, C.S.; Chen, M.A. Undercutting Formation Mechanism in Gas Metal Arc Welding. Weld. J. 2016, 95, 174-184.

31. Abbasi, Z.; Yuhas, D.; Zhang, L.; Basantes, A.-D.-C.; Tehrani, N.N.; Ozevin, D.; Indacochea, E. The Detection of Burn-Through Weld Defects Using Noncontact Ultrasonics. Materials 2018, 11, 128. [CrossRef] [PubMed] 


\title{
Relationship among welding defects
}

\section{with convection and material flow}

dynamic considering principal forces in

plasma arc welding

\author{
Nguyen, Huu Loc
}

MDPI

Nguyen HL, Nguyen AV, Le Duy H, et al., (2021) Relationship among welding defects with convection and material flow dynamic considering principal forces in plasma arc welding.

Metals, Volume 11, Issue 9, September 2021, Article number 1444

https://doi.org/10.3390/met11091444

Downloaded from Cranfield Library Services E-Repository 